\title{
THE ROLE AND SIGNIFICANCE OF 112 EMERGENCY HEALTH SERVICES IN TREATMENT AND GUIDANCE IN MASS FOOD POISONING CASES
}

\author{
Semih Korkut ${ }^{1}$, Nurhayat Baskaya ${ }^{1}$, Elif Arslan², Sakir Omur Hincal ${ }^{3}$, Kenan Ahmet Turkdogan³ \\ ${ }^{1}$ University of Health Sciences, Kartal Lütfi Kırdar Training and Research Hospital, Department of Emergency Medicine, Kartal, Istanbul, Turkey \\ ${ }^{2}$ Provincial Health Directorate of Istanbul, Department of Emergency Health Services Bakirkoy, Istanbul, Turkey \\ ${ }^{3}$ University of Health Science, Bagcilar Training and Research Hospital, Istanbul, Turkey
}

\begin{abstract}
INTRODUCTION: 112 emergency health services send the same types of cases to different hospitals and receive the first information, have a comprehensive knowledge on these cases and inform all the hospitals simultaneously.

AIM: In this study, our aim is to share with the literature through anticholinergic food poisoning cases that it is possible to prevent delays in examination and treatment and to prevent information pollution when 112 emergency health services.

MATERIAL AND METHODS: We retrospectively reviewed 213 mass food poisoning cases which occurred between December 1 and 7, 2019 and which were taken to 14 hospitals with 112 emergency health services. File information of 69 of these cases were reached; in addition to demographic characteristics such as age and gender, physical examination findings such as blood pressure, pulse, skin-eye and consciousness states, laboratory values, hospitalization times, in which units the cases were followed and the duration of admission to the hospital after meals were noted.
\end{abstract}

RESULTS: Of the 69 cases, 42 were found to have skin findings, 37 were found to have mydriasis and 12 were found to have agitation and/or confusion. The duration of admission to hospital after meal was found as $6.5(4.5-10.0)$ hours. $60(87.0 \%)$ of the patients were followed in the emergency room, $4(5.8 \%)$ were followed in the internal medicine service and $5(7.2 \%)$ were followed in the intensive care.

CONCLUSIONS: When the crisis team of 112 emergency health services is alert, they can categorize the event, prevent the chaos in the emergency service of hospitals with correct triage and thus with the process of understanding the event, examination and treatment process becomes more executable.

KEY WORDS: 112 emergency health services, mass food poisoning, anticholinergic toxidromes

Disaster Emerg Med J 2021; 6(3): 125-129

\section{INTRODUCTION}

Anticholinergic toxic syndrome (ATS) does not occur only due to a wide range of drugs, including tricyclic antidepressants, antipsychotics, antihistamines, atropine and scopolamine. It can also occur with the consumption of some plants and their fruits [1]. Atropa belladonna (poisonberry, deadly nightshade) and mandragora autumnalis (mandrake, winter alraune) are a few of these. The fruits and leaves of these plants include high levels of alkaloids, including atropine, 
scopolamine, and hyoscyamine [2]. They competitively block postganglionic parasympathetic muscarinic receptors and muscarinic receptors and cause ATS $[3,4]$.

The most obvious symptoms are caused by the blockage of peripheral muscarinic receptors that innervate exocrine glands, smooth muscles and heart tissue. For this reason, primary toxic symptoms include mydriasis caused by the blockage of the papillary sphincter muscle and the iris muscle; dry mouth secondary to parasympathetic blockage of saliva secretion; tachycardia caused by competition at postganglionic parasympathetic neurons and muscarinic receptors, and receptors at the SA node; fever and erythema due to vasodilation and inhibition of sweating [5]. Direct ocular exposure: "the Gardner syndrome", when the stalk or dried plant material from a member of Datura species enters the eye directly, papillary sphincter and ciliary muscles are affected, causing mydriasis and cycloplegia [5]. While the main symptoms of poisoning are both hallucination and delirium, and high fever, tachycardia and anticholinergic effects, hypertension, convulsions, and coma can be seen in severe cases $[2,6]$.

As with all intoxication methods, the primary approach is patient safety and symptomatic supportive care therapy. Due to the effects of belladona alkaloids on the central nervous system, patients and their relatives should be informed during the first intervention, and they should be taken into the safety circle. In severe cases, a cholinesterase inhibitor, physostigmine, should be used to reverse anticholinergic toxicity [6]. Physostigmine should be given intravenously to an adult at a $0.5-2.0 \mathrm{mg}$ dose at a rate of no more than $1 \mathrm{mg} / \mathrm{min}$; a second dose can be applied if needed. In children, it should be taken intravenously as $0.02 \mathrm{mg} / \mathrm{kg}$ and the rate should not exceed $0.5 \mathrm{mg} / \mathrm{min}[5,7,8]$. Extracorporeal elimination and difficult diuresis can be applied in the treatment, although they are not effective options [5].

The aim of this study is to evaluate the demographic, clinical and laboratory findings and the follow-up time of mass food poisoning. In addition, the aim is to emphasize the effect of pre-hospital emergency health services working in coordination with hospitals on the duration of hospital stay.

\section{MATERIAL AND METHODS}

This retrospective study on alkaloid containing belladona food poisoning history includes 69 patients whose file information was reached from 213 cases evaluated by 112 emergency health services and transferred to hospitals by ambulance in the province of istanbul between December 1 and 7, 2019. Although spinach was mentioned as the common food in the anamnesis of these cases, as a result of the analyses of the samples taken from the points of sale and from the meals cooked at homes conducted by the İstanbul Governorship and the Provincial Directorate of Agriculture and Forestry it was determined that was Mandragora autumnalis was present, which is phenotypically similar to spinach and which is from eggplant family, mixed in spinach.

In addition to the demographic data of the patients such as age and gender, their physical examination findings such as blood pressure (systolic/diastolic), pulse, skin-eye mist and consciousness states, laboratory data (complete blood cell count, alanine aminotransferase (ALT), aspartate aminotransferase (AST), creatine kinase (CK), hospitalization time and in which units they were followed were examined. Comparisons were made between the duration of admission to hospital after meal and age, systolic blood pressure and pulse, follow-up time and age, and the duration of admission to hospital after meal and the follow-up time. Treatments were gastric lavage, activated charcoal, fluid replacement, sedation and supportive therapy.

The patients whose files were not reached were excluded from the study. Permission of the local ethics committee number 2019-22-12 was granted for this study.

\section{Statistical Analysis}

The Kolmogorov-Smirnov test was used to verify the normality of the distribution of continuous variables. Continuous variables were expressed as mean \pm SD or median (min-max) in the presence of abnormal distribution, and categorical variables as percentages. Comparisons between the groups of patients were made using the $\chi^{2}$ test for categorical variables, the independent samples t-test for normally distributed continuous variables, and the Mann-Whitney $U$ test when the distribution was skewed. The correlation was evaluated using the Spearman's correlation test. A $p$ value of 0.05 was considered statistically significant.

\section{RESULTS}

Of the 213 patients with a mean age of 34 (24-49), $57.3 \%$ were female. Systolic, diastolic and pulse val- 
ues of 69 cases whose file information were reached were found as $134.30 \pm 19.44,80.10 \pm 15.90$, $96.94 \pm 17.60$, respectively. All of the patients received symptomatic support care therapy and fluid replacement therapy. Laboratory findings and clinical signs and symptoms of the patients are shown in Table 1. This poisoning picture which has a large number of clinical signs and symptoms presented in $41(19.2 \%)$ of our cases as hot and/or dry skin finding, in $37(17.4 \%)$ of our cases with mydriasis in 12 (5.6\%) of our cases as agitation and/or confusion. Clinical signs and symptoms of syndromes are shown in Table 2.

Median time for admission to hospital after meal was found as $6.5(4.5-10.0)$ hours. The association between hospital admission time after

\begin{tabular}{|c|c|}
\hline & Patient values \\
\hline Leukocyte & $8.7(6.3-11.1)$ \\
\hline Neutrophil & $5.3(2.8-7.9)$ \\
\hline AST & $16.0(15.0-17.0)$ \\
\hline ALT & $16.0(14.0-18.0)$ \\
\hline CK & $150.0(137.0-163.0)$ \\
\hline
\end{tabular}

CK — creatine kinase; ALT — alanine aminotransferase; AST — aspartate aminotransferase meal and age, systolic blood pressure and pulse was found as $p<0.001, r=0.512 ; p=0.361$, $r=0.115 ; p=0.816, r=0.029$, respectively. Time for admission to hospital after meal [median 6.5 (4.5-10.0) hours] and follow-up time were compared, the result was found as $p=0.016$, $r=0.297$.

When the services the patients were followed with were examined, it was found that 60 (87.0\%) patients were followed in emergency services, $4(5.8 \%)$ were followed in the internal medicine services, and $5(7.2 \%)$ were followed in the intensive care. Follow-up time was found as $12,6 \pm 5.9$ hours in the emergency service, $14.0 \pm 6.0$ hours in the internal medicine service and as $27.4 \pm 4.7$ hours in the intensive care. The association between follow-up time and age, systolic blood pressure and pulse were found as $p<0.001, r=0.595$; $p=0.014, r=0.295 ; p=0.206, r=0.154$, respectively.

No significant difference was found in terms of demographic data and laboratory values. The association between duration of admission to hospital after meal and blood pressure and pulse values was found to be significant and the association between duration of admission to hospital after meal and follow-up time was found to be significant.

Table 2. Symptoms and agents of syndromes

\begin{tabular}{|c|c|}
\hline Syndrome & Symptoms \& Agents \\
\hline \multirow[t]{2}{*}{ Cholinergic syndrome } & $\begin{array}{c}\text { Muscarinic syndrome } \\
\text { Symptoms: } \frac{\text { Miosis, } \frac{\text { secretion increase (vomiting, increase in saliva and tear secretion, diarrhea, increase }}{\text { in bronchial secretion), bradycardia }}}{\text { Agents: organic phosphorous insecticides, fungi, carbachol, pilocarpine, physostigmine, carbamate }} \\
\text { insecticides }\end{array}$ \\
\hline & $\begin{array}{l}\text { Nicotinic syndrome } \\
\text { Symptoms: } \text { muscle fasciculations, paralysis, tachycardia, hypertension } \\
\text { Agents: insecticides (halogenated hydrocarbons), nicotine }\end{array}$ \\
\hline Anticholinergic & $\begin{array}{l}\text { Symptoms: } \underline{d r y} \text { skin, } \frac{m y d r i a s i s}{\text { tachycardia }} \underline{\text { hypertension, hyperthermia, difficulty in swallowing, }} \\
\text { urinary retention, delirium, dry armpits, dry mouth, hallucinations, respiratory depression, decrease in } \\
\underline{\text { bowel sounds (ileus) }} \\
\text { Agents: Atropa belladonna alkaloids (atropine, scopolamine), some fungi types (A. muscaria), } \\
\text { antihistaminic, tricyclic antidepressants, phenothiazine, antiparkinsonian drugs, skeletal muscle relaxants }\end{array}$ \\
\hline Sympathomimetic & $\begin{array}{l}\text { Symptoms: convulsions, hypertension, tachycardia, central nervous system excitation (anxiety, tremor, } \\
\text { psychosis), headache, sweating, normal or increased bowel sound. } \\
\text { Agents: cocaine, amphetamines, phencyclidine, LSD, ephedrine, pseudoephedrine, } \\
\text { phenylpropanolamine, theophylline, caffeine }\end{array}$ \\
\hline Withdrawal & Symptoms: piloerection, tachycardia, secretion increase, convulsions, hallucinations, mydriasis, cramps \\
\hline Opioid, ethanol intox. & $\begin{array}{r}\text { Symptoms: coma, respiratory depression, miosis, } \\
\text { decrease in bowel sound, hyporeflexia } \\
\text { Agents: opioid analgesics, barbiturates, meprobamate, ethanol benzodiazepines, clonidine, amitraz } \\
\text { (insecticide) }\end{array}$ \\
\hline
\end{tabular}




\section{DISCUSSION}

While intoxication with Atropa belladonna and similar plants occurs in adults for hallucinogenic effect or as a means of suicide, most of the time it occurs accidentally in children [3]. A common belief in our country is that using its leaves for tea is beneficial for stomach and intestinal problems due to its antispasmodic characteristics [9]. Basically, the alkaloids included in the plant (L-atropine, DL-hyoscyamine and hyoscine) cause confusion or acute psychosis $[10,11]$. While the symptoms of poisoning include hallucination, delirium, high fever, tachycardia, and anticholinergic effects, hypertension, convulsions, coma and death can be seen in severe cases $[2,12]$. In a series of eight cases showing poisoning with Atropa belladonna L. conducted by Schneider et al. [13], three of the four adults had visual hallucinations and delirium, while one of these later fell into a coma and required mechanical ventilation. In the retrospective study by Bektaş MS et al. [14], which included 108 cases, age at the time of admission, age groups, gender, signs and symptoms caused by poisoning, hospitalization time, laboratory data, intensive care needs and the treatment given were recorded. $44.4 \%$ of the patients were female, while $55.6 \%$ were male. The most common symptoms were xeroderma and flushing, while the most common symptoms were tachycardia and mydriasis. In their study they presented as a series, leukocytosis in three cases, hyperglycemia in seventeen cases and slightly increased serum aspartate transaminase elevations in four cases [15].

To the best of our knowledge, in this study, anticholinergic toxidrome cases related to belladonna alkaloids have been associated with pre-hospital 112 emergency health services for the first time.

In addition to values of vitals in our patients, their central and peripheral findings supported the presence of an anticholinergic toxidrome. The anticholinergic syndrome can occur due to drugs or substances which inhibit acetylcholine from binding to muscarinic receptors [16]. These drugs include antihistaminics, drugs used for Parkinson's disease, and antipsychotics; however, detailed anamnesis of our patients did not include a history of drugs. The treatment of Atropa belladonna poisoning is conservative. Close monitoring is recommended in a silent environment. Conservative treatment is based on maintaining airway patency and respiratory and circulation support [16]. Conservative treatment and activated charcoal was applied in all our patients.

Recently, the fact that many similar cases were evaluated by 112 emergency health services and transferred to hospitals brought to mind the possibility that a public health problem may have arisen. Accordingly, coordination between 112 emergency services crisis center and 14 hospitals was ensured, the possible chaos that could occur in the emergency services was prevented and the follow-up and treatment process was prevented from failing.

\section{CONCLUSION}

In cases with unconsciousness and fatigue, as well as psychotic symptoms, during the first intervention, detailed anamnesis by 112 emergency health services crisis center and 112 teams working on site, and evaluation of consciousness and vital parameters with physical examination is very valuable in differential diagnosis. In addition, the continuous coordination between 112 emergency health services crisis center, field teams and hospitals is the most suitable organization that can prevent the problems that may occur during the process of treatment and follow-up in hospitals, especially emergency service and intensive care units by predicting the possible public health problems which can be caused by contemporary social and regional problems.

\section{REFERENCES}

1. Heindl S, Binder C, Desel $H$, et al. [Etiology of initially unexplained confusion of excitability in deadly nightshade poisoning with suicidal intent. Symptoms, differential diagnosis, toxicology and physostigmine therapy of anticholinergic syndrome]. Dtsch Med Wochenschr. 2000; 125(45): 1361-1365, doi: 10.1055/s-2000-8178, indexed in Pubmed: 11109424.

2. Southgate HJ, Egerton M, Dauncey EA. Lessons to be learned: a case study approach. Unseasonal severe poisoning of two adults by deadly nightside (Atropa belladonna). J R Soc Promot Health. 2000; 120(2): 127-130, doi: 10.1177/146642400012000212, indexed in Pubmed: 10944889.

3. Trabattoni G, Visintini D, Terzano GM, et al. Accidental poisoning with deadly nightshade berries: a case report. Hum Toxicol. 1984; 3(6): 513-516, doi: 10.1177/096032718400300607, indexed in Pubmed: 6526400.

4. Joshi P, Wicks AC, Munshi SK. Recurrent autumnal psychosis. Postgrad Med J. 2003; 79(930): 239-240, doi: 10.1136/pmj.79.930.239, indexed in Pubmed: 12743348. 
5. Krenzelok E. Aspects ofDaturapoisoning and treatment. Clinical Toxicology. 2010; 48(2): 104-110, doi: 10.3109/15563651003630672.

6. Burns $\mathrm{MJ}$, Linden $\mathrm{CH}$, Graudins $\mathrm{A}$, et al. A comparison of physostigmine and benzodiazepines for the treatment of anticholinergic poisoning. Ann Emerg Med. 2000; 35(4): 374-381, doi: 10.1016/501960644(00)70057-6, indexed in Pubmed: 10736125.

7. Anonymous. Physostigmine. Lexi-Comp Online. Hudson, $\mathrm{OH} .2000$.

8. American Hospital Formulary Service. American Journal of Health-System Pharmacy. 1959; 16(10): 541-541, doi: 10.1093/ ajhp/16.10.541.

9. Demirhan A, Tekelioğlu ÜY, Yıldız İ, et al. Anticholinergic Toxic Syndrome Caused by Atropa Belladonna Fruit (Deadly Nightshade): A Case Report. Turk J Anaesthesiol Reanim. 2013; 41(6): 226-228, doi: 10.5152/TJAR.2013.43, indexed in Pubmed: 27366377.

10. Lange A, Toft P. Poisoning with nightside, Atropa belladona. Ugeskr Laeger. 1990; 152: 1096.

11. Perlik-Gattner I. Atropa belladona poisoning suggesting severe post - traumatic brain damage. Przegl Lek. 1997; 54: 464-65.
12. Lamminpää A, Kinos M. Plant poisonings in children. Hum Exp Toxicol. 1996; 15(3): 245-249, doi: 10.1177/096032719601500310, indexed in Pubmed: 8839213.

13. Schneider $F$, Lutun $P$, Kintz $P$, et al. Plasma and urine concentrations of atropine after the ingestion of cooked deadly nightshade berries. J Toxicol Clin Toxicol. 1996; 34(1): 113-117, doi: 10.3109/15563659609020245, indexed in Pubmed: 8632502.

14. MS Bektaş, F Aktar, A Güneş, Ü Uluca, S Gülşen, K Karaman. Atropa belladona poisoning in chilhood. West Indian Med J Doi: 0.7727/ wimj. ; 2015: 457.

15. Caksen $H$, Odabaş $D$, Akbayram $S$, et al. Deadly nightshade (Atropa belladonna) intoxication: an analysis of 49 children. Hum Exp Toxicol. 2003; 22(12): 665-668, doi: 10.1191/0960327103ht4040a, indexed in Pubmed: 14992329.

16. Cikla U, Turkmen S, Karaca Y, et al. An Atropa belladonna L. poisoning with acute subdural hematoma. Hum Exp Toxicol. 2011; 30(12): 1998-2001, doi: 10.1177/0960327111407225, indexed in Pubmed: 21540312 